\title{
Emodin inhibits the progression of acute pancreatitis via regulation of IncRNA TUG1 and exosomal IncRNA TUG1
}

\author{
XIUMEI WEN ${ }^{1}$, BEIHUI HE ${ }^{2}$, XING TANG $^{3}$, BIN WANG $^{3}$ and ZHIYUN CHEN ${ }^{2}$ \\ ${ }^{1}$ Department of Gastroenterology, Liangzhu Hospital, Hangzhou, Zhejiang 311113; ${ }^{2}$ The Second Central Laboratory, \\ The First Affiliated Hospital of Zhejiang Chinese Medical University, Hangzhou, Zhejiang 310006; ${ }^{3}$ Department of Emergency, \\ The Third Affiliated Hospital of Zhejiang Chinese Medical University, Hangzhou, Zhejiang 310005, P.R. China
}

Received December 3, 2020; Accepted June 10, 2021

DOI: $10.3892 / \mathrm{mmr} .2021 .12425$

\begin{abstract}
Acute pancreatitis (AP) is one of the most frequent gastrointestinal diseases and has no specific treatment. It has been shown that dysfunction of pancreatic acinar cells can lead to AP progression. Emodin is a natural product, which can alleviate the symptoms of AP. However, the mechanism by which emodin regulates the function of pancreatic acinar cells remains unclear. Thus, the present study aimed to investigate the mechanism by which emodin modulates the function of pancreatic acinar cells. To mimic AP in vitro, pancreatic acinar cells were cotreated with caerulein and lipopolysaccharide (LPS). Exosomes were isolated using the ExoQuick precipitation kit. Western blot analysis, Nanosight Tracking analysis and transmission electron microscopy were performed to detect the efficiency of exosome separation. Gene expression was detected by reverse transcription-quantitative PCR. The levels of IL-1 $\beta$ and TNF- $\alpha$ were detected by ELISA. The data indicated that emodin significantly decreased the levels of IL-1 $\beta$ and TNF- $\alpha$ in the supernatant samples derived from AR42J cells cotreated with caerulein and LPS. In addition, emodin significantly promoted the proliferation of AR42J cells cotreated with caerulein and LPS, and inhibited apoptosis, while the effect of emodin was reversed by long non-coding (lnc)RNA taurine upregulated 1 (TUG1) overexpression. The expression level of TUG1 in AR42J cells or exosomes derived from AR42J cells was significantly increased following treatment of the cells with LPS and caerulein, while this effect was notably reversed by emodin treatment. In addition, exosomes derived from caerulein and LPS cotreated AR42J cells inhibited the differentiation and anti-inflammatory function of regulatory $\mathrm{T}$ cells, while treatment of the cells with emodin significantly decreased this
\end{abstract}

Correspondence to: Dr Zhiyun Chen, The Second Central Laboratory, The First Affiliated Hospital of Zhejiang Chinese Medical University, 54 Youdian Road, Hangzhou, Zhejiang 310006, P.R. China

E-mail: chenzhiyun123@126.com

Key words: exosome, inflammatory response, pancreatic acinar cells, regulatory $\mathrm{T}$ cells effect. In conclusion, the data indicated that emodin inhibited the induction of inflammation in AR42J cells by regulating the expression of cellular and exosomal lncRNA. Therefore, emodin may be used as a potential agent for the treatment of AP.

\section{Introduction}

Acute pancreatitis (AP) is a type of inflammatory disease, which results from the dysregulation of pancreatic enzymes in the pancreas $(1,2)$. AP is very common, has a considerably high mortality rate and can cause systemic complications (3). The mortality rate of AP has increased from 15 to $30 \%$ (4), while the combination of AP with sepsis increases the mortality rate to $>50 \%$ (5). Although significant efforts have been made to prevent and treat AP (6), no specific treatment methods are currently available. The development of the inflammatory response in pancreatic acinar cells correlates with the progression of AP (7). Therefore, inhibition of the inflammation in pancreatic acinar cells is crucial for the treatment of AP.

Emodin (1,3,8-Trihydroxy-6-methylanthra-quinone) is a natural product, which originates from Rheum palmatum. Previous studies have reported that emodin exhibits anti-inflammatory effects $(8,9)$. In addition, it has been revealed that emodin can alleviate the symptoms of AP (10). However, the underlying mechanism by which emodin regulates the progression of AP remains unclear.

Long non-coding RNAs (lncRNAs) can play important roles in the development of multiple diseases $(11,12)$. Moreover, lncRNAs participate in the prevention of AP. For example, Zhu et al (13) demonstrated that lncRNA maternally expressed 3 alleviated caerulein-induced inflammatory injury in human pancreatic cells. In addition, IncRNA cancer susceptibility 2 has been reported to be involved in the progression of AP (14). Furthermore, the expression levels of lncRNA taurine upregulated 1 (TUG1) are upregulated in pancreatic tissues (15). However, the role of TUG1 in the development of AP is yet to be fully elucidated.

Exosomes are a type of extracellular vesicles, which can be secreted by cells and promote the transfer of molecules to cells $(16,17)$. In addition, exosomes play key roles in the progression of multiple diseases $(18,19)$. A previous report indicated that exosomes can regulate the progression of 
AP (20). However, the underlying mechanism requires further investigation.

It has been reported that dysregulation of immune responses may lead to the progression of AP $(21,22)$. Guo et al $(23)$ highlighted that the T helper 17 (Th17) cell/regulatory T cell (Treg) imbalance was involved in the development of AP and that it may be correlated with its severity and prognosis (24). Therefore, Treg cells play a key role in mediating the progression of AP. In addition, it has been shown that TUG1 regulates Treg cell differentiation (25). Based on this evidence, the present study aimed to explore the association between emodin and Treg cells in AP.

In the current study, the effects of emodin on AR42J cells cotreated with caerulein and lipopolysaccharide (LPS) were investigated. The present study aimed to provide a novel treatment strategy for AP.

\section{Materials and methods}

Cell culture. Rat pancreatic acinar cell lines (AR42J) were purchased from Tongpai (Shanghai) Biotechnology Co., Ltd. and maintained in DMEM (Thermo Fisher Scientific, Inc.) containing $10 \%$ FBS (26), $1 \%$ penicillin and $1 \%$ streptomycin (Thermo Fisher Scientific, Inc.) at $37^{\circ} \mathrm{C}$ with $5 \% \mathrm{CO}_{2}$. To mimic AP in vitro, AR42J cells were treated with LPS (10 $\mu \mathrm{g} / \mathrm{ml}$; Beijing Solarbio Science \& Technology Co., Ltd.) and caerulein (100 nM; Beijing Solarbio Science \& Technology Co., Ltd.) for $3 \mathrm{~h}$, as previously described (27).

Cell transfection. AR42J cells $\left(3 \times 10^{5}\right.$ cells/well) were transfected with pcDNA3.1 (negative control; NC; $1 \mu \mathrm{g} / \mu \mathrm{l}$ ) or pcDNA3.1-TUG1 [1 $\mu \mathrm{g} / \mu 1$, TUG1 overexpression (OE)] using Lipofectamine $^{\circledR} 2000$ (Invitrogen; Thermo Fisher Scientific, Inc.) at $37^{\circ} \mathrm{C}$ for $48 \mathrm{~h}$. pcDNA3.1 and pcDNA3.1-TUG1 were purchased from Shanghai GenePharma Co., Ltd. After $48 \mathrm{~h}$ of transfection, the transfected cells were used for subsequent analysis.

Exosome isolation. Briefly, AR42J cells were cotreated with LPS $(10 \mu \mathrm{g} / \mathrm{ml})$ and caerulein $(100 \mathrm{nM})$ at $37^{\circ} \mathrm{C}$ for $3 \mathrm{~h}$. Then, AR42J cells $\left(3 \times 10^{5}\right.$ cells/well) or AR42J cells cotreated with LPS and caerulein were centrifuged at $300 \mathrm{x}$ g for $15 \mathrm{~min}$, $2,000 \mathrm{x}$ g for $15 \mathrm{~min}$, and $10,000 \mathrm{x} \mathrm{g}$ for $30 \mathrm{~min}$ at room temperature to collect the supernatant. The samples were filtered with a $0.22-\mu \mathrm{m}$ filter and collected to isolate exosomes via ultracentrifugation at $4^{\circ} \mathrm{C}(120,000 \mathrm{x}$ g for $70 \mathrm{~min})$. For collection of the pellet, the samples were centrifuged at $10,000 \times \mathrm{g}$ for $1 \mathrm{~h}$ at $4^{\circ} \mathrm{C}$. Then, the pellet was resuspended in PBS for further analysis. Meanwhile, the particle sizes of exosomes were investigated by Nanoparticle Tracking Analysis (NTA), the structure of exosomes was observed by transmission electron microscopy (TEM) and the exosome markers were detected by western blotting. Exosomes isolated from AR42J cells were the control-exo group; exosomes isolated from AR42J cells cotreated with LPS and caerulein were the AP-exo group.

Reagents. Emodin was purchased from Beijing Solarbio Science \& Technology Co., Ltd. IL-2 (cat. no. SRP3242) and anti-CD3 (cat. no. SAB4700040)/CD28 (cat. no. SAB4700739) were purchased from Sigma-Aldrich; Merck KGaA. Caerulein was obtained from MedChemExpress. Meanwhile, ARJ21 cells were treated with 20 and $40 \mu \mathrm{M}$ emodin, according to previous references $(28,29)$.

TEM. The exosome pellet was incubated for $5 \mathrm{~min}$ and subsequently immersed in $2 \%$ phosphotungstic acid solution for $1 \mathrm{~min}$. The pellet was fixed using $2.5 \%$ glutaraldehyde (pH 7.2) at $4^{\circ} \mathrm{C}$ overnight. Then, $100 \mu \mathrm{l}$ suspension was placed on a parafilm sheet and a copper grid coated with carbon was placed onto the drop for $10 \mathrm{sec}$ and then removed. The grid was then rinsed 10 times with $\mathrm{MiliQ} \mathrm{H}_{2} \mathrm{O}$ (1 min each) at room temperature. Subsequently, the grid was laid on a drop of uranyl acetate ( $\mathrm{pH} 7.0$; cat. no. 2624; SPI-CHEM) at room temperature for $10 \mathrm{~min}$. After rinsing with Milli-Q $\mathrm{H}_{2} \mathrm{O}$ and methylcellulose uranyl ( $\mathrm{pH} 4.0)$, the grid was incubated at room temperature for 10 min on a drop of methylcellulose uranyl $(\mathrm{pH} \mathrm{4.0,}$ cat. no. M-6385; Sigma-Aldrich; Merck KGaA). Finally, the grid was dried for $10 \mathrm{~min}$ at room temperature and observed using a transmission electron microscope (JEOL, Ltd.).

Cell Counting Kit-8 (CCK-8) assay. The viability of AR42J cells $\left(5 \times 10^{3} /\right.$ well $)$ was determined in each group using the CCK-8 assay (Beyotime Institute of Biotechnology). In brief, ARJ21 cells were plated $\left(5 \times 10^{3}\right.$ cells/well) into 96 -well plates and treated for $0,24,48$ or $72 \mathrm{~h}$ at $37^{\circ} \mathrm{C}$. Subsequently, cells were incubated with $10 \mu \mathrm{lCCK}-8$ reagents for $2 \mathrm{~h}$ at $37^{\circ} \mathrm{C}$. The optical density values were measured at $450 \mathrm{~nm}$ using a microplate reader to assess cell viability.

Cell apoptosis analysis. The early + late apoptosis of AR42J cells was detected by flow cytometry. In brief, AR42J cells (1x10 4 per well) were trypsinized, washed with PBS and resuspended in binding buffer. Subsequently, the cells were stained with $5 \mu 1$ Annexin V-FITC and PI (BD Biosciences) in the dark at $37^{\circ} \mathrm{C}$ for $30 \mathrm{~min}$. Flow cytometry (FACScan ${ }^{\mathrm{TM}}$; BD Biosciences) was applied to investigate the apoptotic rate using FlowJo (version 10.6.2; BD Biosciences).

Western blot analysis. Total protein was isolated from cell lysates using RIPA buffer (Beyotime Institute of Biotechnology). The protein was quantified by the BCA protein kit (Thermo Fisher Scientific, Inc.). Subsequently, the proteins (30 $\mu \mathrm{g} /$ lane) were separated with SDS-PAGE gel (10\%) and separated proteins were subsequently transferred to PVDF membranes, which were incubated with primary antibodies overnight at $4{ }^{\circ} \mathrm{C}$ following blocking with $3 \%$ non-fat milk at room temperature for $1 \mathrm{~h}$. The membranes were incubated with Goat Anti-Rabbit antibody (HRP-conjugated, 1:5,000; cat. no. ab7090; Abcam) at room temperature for $1 \mathrm{~h}$, scanned by an Odyssey Imaging System (Thermo Fisher Scientific, Inc.) and analyzed with ImageJ software (version 1.8.0; National Institutes of Health). The primary antibodies used in the present study were as follows: Anti-CD63 (1:1,000; cat. no. ab134045; Abcam), anti-Calnexin (1:1,000; cat. no. ab133615; Abcam), anti-IL-10 (1:1,000; cat. no. ab133575; Abcam), anti-TGF- $\beta$ (1:1,000; cat. no. ab215715; Abcam) and anti- $\beta$-actin (1:1,000; cat. no. ab8226; Abcam). All the antibodies used were purchased from Abcam.

Reverse transcription-quantitative PCR (RT-qPCR). Total RNA from cells or exosomes was isolated using the TRIzol ${ }^{\circledR}$ 
reagent (Invitrogen; Thermo Fisher Scientific, Inc.) and the exoRNeasy Midi kit (Qiagen, Inc.). The All-in-One ${ }^{\mathrm{TM}}$ First-Strand cDNA Synthesis kit (GeneCopoeia, Inc.) was used to transcribe total RNA into cDNA according to the manufacturer's protocol. RT-qPCR was performed using the SYBR ${ }^{\mathrm{TM}}$ Green Master Mix (Qiagen, Inc.). qPCR was performed in triplicate under the following protocol: $2 \mathrm{~min}$ at $94^{\circ} \mathrm{C}$, followed by 35 cycles for $30 \mathrm{sec}$ at $94^{\circ} \mathrm{C}$ and $45 \mathrm{sec}$ at $55^{\circ} \mathrm{C}$. The $2^{-\Delta \Delta \mathrm{Cq}}$ method (30) was used to quantify the data and GAPDH was used for normalization. The primer sequences used were as follows: TUG1 forward (F), 5'-ATCTAATCAGTAAGC GGA-3' and reverse (R), 5'-AAAGCAAGTCAAGACCTC-3'; IL-10 F, 5'-GAA AAATTGAACCACCCGGCA-3' and R, 5'-TTCCAAGGAGTTGCTCCCGT-3'; TGF- $\beta$ F, 5'-CTG CTGACCCCCACTGATAC-3' and R, 5'-AGCCCTGTATTC CGTCTCCT-3'; and GADPH F, 5'-ACAGCAACAGGGTGG TGGAC-3' and R, 5'-TTTGAGGGTGCAGCGAACTT-3'.

NTA. The hydrodynamic radius and concentration of exosomes were detected via NTA, as previously described (31). In brief, a total of $\sim 0.3 \mathrm{ml}$ supernatant was loaded into the sample chamber of an LM10 Nanosight unit (Nanosight, Ltd.) and three videos of either 30 or $60 \mathrm{sec}$ were recorded of each sample. Data analysis was performed using NTA 2.1 software (Nanosight, Ltd.). The paths of unlabeled particles acting as point scatterers undergoing Brownian motion in a $0.25 \mathrm{ml}$ chamber through which a $635-\mathrm{nm}$ laser beam is passed were determined from a video recording, with the mean squared displacement determined for each possible particle. The diffusion coefficient and sphere-equivalent hydrodynamic radius were subsequently determined using the Stokes-Einstein equation.

ELISA. The levels of IL-6 (cat. no. SEA079Ra), IL-1 $\beta$ (cat. no. SEA563Ra) and TNF- $\alpha$ (cat. no. SEA133Ra) in the serum of mice or the cell supernatants were detected using ELISA kits (Wuhan USCN Business Co., Ltd.). The cell supernatants were harvested by centrifugation $\left(500 \mathrm{x} \mathrm{g}, 4^{\circ} \mathrm{C}, 10 \mathrm{~min}\right)$. Subsequently, cells were incubated with a secondary antibody (cat. no. BA1054; Wuhan Boster Biological Technology, Ltd.) at room temperature for $1 \mathrm{~h}$. Finally, following incubation with hydrochloric acid at room temperature for $5 \mathrm{~min}$, the absorbance was measured using a microplate reader.

Animal experiments. A male Wistar rat (12-weeks-old, $200 \mathrm{~g}$ ) was obtained from The Chinese Academy of Sciences. The rat was housed within a dedicated specific pathogen-free (SPF) facility (it was raised in standard cages with 12-h light/dark cycle, a constant temperature of $23 \pm 1^{\circ} \mathrm{C}$ and a humidity of $50-60 \%$ ) and had free access to food and water. The protocols for care and use of laboratory animals were approved by the Zhejiang Chinese Medical University (Hangzhou, China). The rat was euthanized using $\mathrm{CO}_{2}$ at a displacement rate of $30 \%$ of the chamber volume $/ \mathrm{min}\left(\mathrm{CO}_{2}\right.$ flow rate, $\left.2.5 \mathrm{l} / \mathrm{min}\right)$. Then, peripheral blood mononuclear cells (PBMCs, $5 \mathrm{ml}$ ) were collected. PBMCs were collected as described in a previous study (32). In brief, $\mathrm{CD}^{+}{ }^{+} \mathrm{T}$ cells were isolated from PBMCs, and then $\mathrm{CD}^{+}{ }^{+} \mathrm{T}$ cells were treated with $10 \mathrm{ng} / \mathrm{ml} \mathrm{IL-2} \mathrm{and}$ $2 \mu \mathrm{g} / \mathrm{ml}$ anti-CD3/CD28 for $72 \mathrm{~h}$ in order to induce the activation of Treg cells (33).
BALB/c mice ( $\mathrm{n}=18$, male, 28-35 g; age, 6-8 weeks) were purchased from Beijing Vital River Laboratory Animal Technology Co., Ltd. All mice were maintained under SPF conditions. All procedures performed in this study involving animals were in accordance with the National Institutes of Health Guide for the Care and Use of Laboratory Animals (34). The animal experiments were approved by the Animal Care and Use Committee of The First Affiliated Hospital of Zhejiang Chinese Medical University (approval no. 20210201003B). To mimic AP in vivo, mice were fasted for $12 \mathrm{~h}$, and a mouse model of AP was constructed according to a previous method (35). Briefly, mice in the AP group were injected intraperitoneally with $50 \mu \mathrm{g} / \mathrm{kg}$ caerulein 12 times $(0.2 \mathrm{ml} / \mathrm{mice}$, each time interval was $1 \mathrm{~h})$. In addition, mice in the control group were injected with saline with the same procedure. Meanwhile, before the second injection and after the eighth injection of caerulein, emodin $(40 \mathrm{mg} / \mathrm{kg})$ was injected intraperitoneally into mice (AP + emodin group). The mice were sacrificed $48 \mathrm{~h}$ after the last injection of caerulein, and the tissues and serum were then collected. All mice were euthanized using $\mathrm{CO}_{2}$ at a displacement rate of $30 \%$ of the chamber volume/min $\left(\mathrm{CO}_{2}\right.$ flow rate, $\left.2.5 \mathrm{l} / \mathrm{min}\right)$.

To evaluate the effects of emodin in AP mice, inflammatory factor (IL-1 $\beta$, IL- 6 and TNF- $\alpha$ ) contents in serum of mice were detected with the ELISA kits, as mentioned above.

Hematoxylin and eosin $(H \& E)$ staining. H\&E staining was used to observe pancreatic injury and inflammation as previously described (36). Paraffin-embedded tissues were cut to $4 \mu \mathrm{m}$ thickness, deparaffinized, rehydrated and stained with $H \& E$ using standard procedures. The slides were then mounted with BioMount mounting media and observed under a light microscope (Olympus Corporation).

Isolation of $\mathrm{CD}^{+} T$ cells. A total of $2 \times 10^{6} \mathrm{PBMCs} / \mathrm{ml}$ were seeded in 6-well cell culture plates. The cells were treated with 50 ng/ml Phorbol-12-myristate-13-acetate (Beijing Solarbio Science \& Technology Co., Ltd.), Ionomycin ( $2 \mu \mathrm{g} / \mathrm{ml}$; Beijing Solarbio Science \& Technology Co., Ltd.) and Brefelin ( $2 \mu \mathrm{g} / \mathrm{ml}$; Beijing Solarbio Science \& Technology Co., Ltd.). These reagents were incubated with the cells at $37^{\circ} \mathrm{C}$ for $4 \mathrm{~h}$. The $\mathrm{CD}^{+} \mathrm{T}$ cell population was isolated from the cell cultures by immunomagnetic selection (MidiMACS ${ }^{\mathrm{TM}}$ Separator; Thermo Fisher Scientific, Inc.).

Flow cytometry. To further induce the differentiation of Treg cells, CD $4^{+} \mathrm{T}$ cells $\left(5 \times 10^{3} /\right.$ well $)$ were treated with anti-CD3 (cat. no. SAB4700040)/anti-CD28 (cat. no. SAB4700739; $2 \mu \mathrm{g} / \mathrm{ml}$; Sigma-Aldrich; Merck KGaA) and IL-2 $(10 \mathrm{ng} / \mathrm{ml}$; Sigma-Aldrich; Merck KGaA) at $37^{\circ} \mathrm{C}$ for $72 \mathrm{~h}$. The cell suspension was collected and the cells were incubated with anti-CD4 (labeled with FITC; cat. no. 11-0040-82; Thermo Fisher Scientific, Inc.) and anti-CD25 (labeled with PE; cat. no. MA1-90766; Thermo Fisher Scientific, Inc.) for $30 \mathrm{~min}$. Subsequently, the cells were centrifuged at $3,000 \mathrm{x} \mathrm{g}$ at $4^{\circ} \mathrm{C}$ for $10 \mathrm{~min}$, washed and fixed with $4 \%$ paraformaldehyde for $20 \mathrm{~min}$ at $4^{\circ} \mathrm{C}$. The samples were resuspended and incubated with anti-FOXP3 antibody (labeled with APC; cat. no. 17-5773-82; Thermo Fisher Scientific, Inc.) for $30 \mathrm{~min}$ at $4^{\circ} \mathrm{C}$. Finally, the cells were centrifuged at $3,000 \times$ g at $4^{\circ} \mathrm{C}$ for $10 \mathrm{~min}$, washed, fixed with $4 \%$ paraformaldehyde at $4^{\circ} \mathrm{C}$ 
for $10 \mathrm{~min}$ and the ratio of $\mathrm{CD} 4^{+} / \mathrm{CD} 25^{+} / \mathrm{FOXP}^{+} \mathrm{T}$ cells was measured by FACS (FACSLyric ${ }^{\mathrm{TM}}$; BD Biosciences). FlowJo (version 10.6.2; BD Biosciences) was used to analyze the data.

Statistical analysis. All data are expressed as the mean \pm SEM. The CCK-8 assay was performed five times. Western blotting, ELISA, RT-qPCR and flow cytometry assays were performed in triplicate. One-way ANOVA followed by the Tukey's post hoc test were used for comparisons between $\geq 3$ groups. $\mathrm{P}<0.05$ was considered to indicate a statistically significant difference.

\section{Results}

AP in vitro model. To mimic AP in vitro, AR42J cells were cotreated with caerulein and LPS. The levels of IL-1 $\beta$ and TNF- $\alpha$ in the supernatants of AR42J cells were significantly increased following treatment of the cells with caerulein and LPS (Fig. 1A and B). The data suggested that the in vitro model of AP was successfully established.

IncRNA TUG1 expression is upregulated in AR42J cells cotreated with caerulein and LPS and in exosomes derived from caerulein and LPS pretreated AR42J cells. The separation efficiency of exosomes was examined by TEM. Exosomes demonstrated disc-shaped crescent-shaped and double-layered membrane structure (Fig. 2A). In addition, the expression levels of CD63 were notably higher in the AP-exo group than those noted in the control-exo, while western blotting demonstrated the absence of calnexin expression in the control-exo and AP-exo groups (Fig. 2B). In addition, rounded particles of $\sim 80-100 \mathrm{~nm}$ in diameter were noted following treatment of the cells with LPS and caerulein (Fig. 2C). The data suggested that exosomes were successfully separated from AR42J cells. Furthermore, the expression levels of TUG1 in AR42J cells and exosomes derived from AR42J cells were significantly increased following treatment of the cells with caerulein and LPS (Fig. 2D and E). In summary, the data indicated that lncRNA TUG1 expression was upregulated in caerulein and LPS pre-treated AR42J cells and exosomes derived from AR42J cells cotreated with caerulein and LPS.

Emodin inhibits the expression of IncRNA TUG1 in cells cotreated with LPS and caerulein and exosomes derived from the aforementioned cell samples. The effects of emodin on AR42J cell viability were assessed using the CCK-8 assay. The viability of AR42J cells was significantly inhibited by caerulein and LPS, while the effects of caerulein and LPS were reversed following treatment of the cells with 20 or $40 \mu \mathrm{M}$ emodin (Fig. 3A). In addition, the apoptotic rate of AR42J cells cotreated with caerulein and LPS was significantly inhibited following treatment of the cells with 20 or $40 \mu \mathrm{M}$ emodin (Fig. 3B). Moreover, ELISA demonstrated that the levels of IL- $1 \beta$ and TNF- $\alpha$ in supernatants derived from AR42J cells were significantly increased following treatment of the cells with caerulein and LPS, while application of 20 or $40 \mu \mathrm{M}$ emodin significantly reversed this effect (Fig. $3 \mathrm{C}$ and D). Furthermore, caerulein and LPS significantly increased the levels of TUG1 in AR42J cells or exosomes derived from AR42J cells, while their effects were significantly reversed by
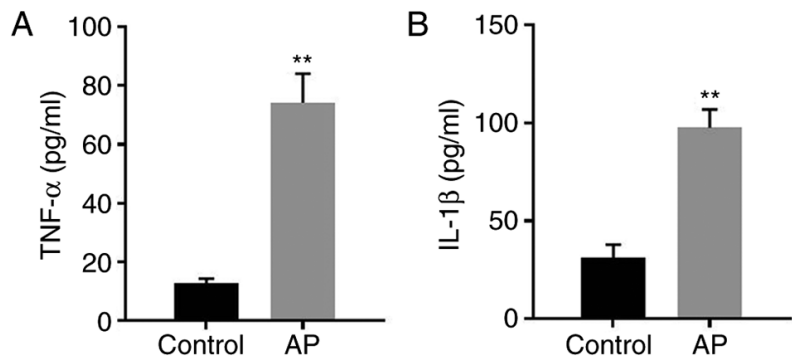

Figure 1. Successful establishment of the in vitro model of AP. AR42J cells were treated with lipopolysaccharide $(10 \mu \mathrm{g} / \mathrm{ml})$ and caerulein $(100 \mathrm{nM})$ for $3 \mathrm{~h}$. Then, the levels of (A) TNF- $\alpha$ and (B) IL-1 $\beta$ in the supernatants of AR42J cells were detected by ELISA. ${ }^{* *} \mathrm{P}<0.01$ vs. control. AP, acute pancreatitis.

emodin treatment of the cells ( 20 or $40 \mu \mathrm{M}$; Fig. 3E and F). Since AR42J cells were more sensitive to $40 \mu \mathrm{M}$ emodin, this concentration was selected for subsequent analysis. Taken together, the data indicated that emodin inhibited the expression levels of cellular and exosomal TUG1 in AR42J cells cotreated with caerulein and LPS.

TUG1 overexpression induces apoptosis and significantly reverses the effects of emodin on the viability of AR42J cells, which were pretreated with caerulein and LPS. To investigate the effects of TUG1 on emodin-treated AR42J cells, cells were transfected with a TUG1 OE plasmid. The expression levels of TUG1 were upregulated following transfection of AR42J cells with TUG1 OE (Fig. 4A). Moreover, overexpression of TUG1 caused a significant reduction in the emodin-induced increase of AR42J cell viability following treatment with caerulein and LPS (Fig. 4B). The inhibitory effect of emodin on the induction of apoptosis in AR42J cells cotreated with caerulein and LPS was significantly reduced following overexpression of TUG1 (Fig. 4C). In conclusion, TUG1 overexpression reversed the effects of emodin on the proliferation of AR42J cells cotreated with caerulein and LPS by inducing cell apoptosis.

Emodin promotes the differentiation of Treg cells by inhibition of TUG1 in exosomes derived from AR42J cells cotreated with caerulein and LPS. In order to confirm whether emodin mediates Treg cell differentiation via regulation of exosomal TUG1, RT-qPCR was performed. The expression levels of TUG1 in $\mathrm{CD} 4^{+} \mathrm{T}$ cells cotreated with anti-CD3/anti-CD28 and IL-2 were significantly increased by AP-exo (exosomes derived from AR42J cells cotreated with LPS and caerulein), while the effects of AP-exo were reversed by emodin treatment (Fig. 5A). In addition, the ratio of $\mathrm{CD}^{+} / \mathrm{CD} 25^{+} / \mathrm{FOXP}^{+} \mathrm{T}$ cells in $\mathrm{CD} 4^{+} \mathrm{T}$ cells was significantly increased following their combined treatment with anti-CD3/anti-CD28 and IL-2, while this effect was reversed by AP-exo treatment (Fig. 5B and C). Moreover, emodin significantly inhibited the effects of AP-exo on Treg cell differentiation (Fig. 5B and C). The expression levels of IL- 10 and TGF- $\beta$ in CD $4^{+}$T cells were notably increased by combined treatment of anti-CD3/anti-CD28 and IL-2, while these effects were partially reversed by AP-exo treatment (Fig. 5D-F). However, emodin restored the effects of anti-CD3/anti-CD28 and IL-2 (Fig. 5D-F). In summary, emodin may promote the differentiation of Treg cells by inhibition of exosomal lncRNA TUG1 expression. 
A

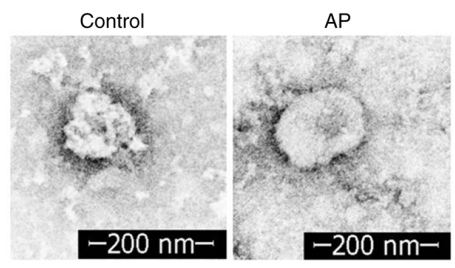

B

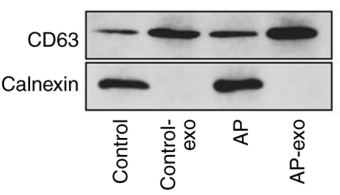

C $E 7$

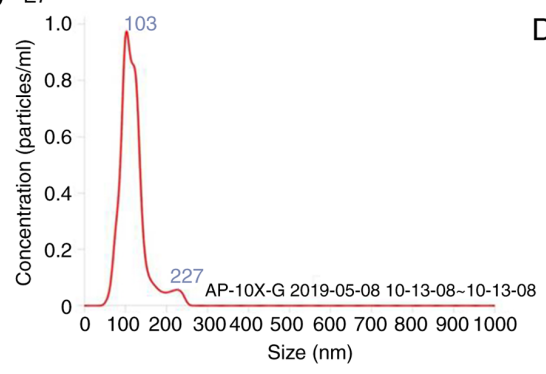

D

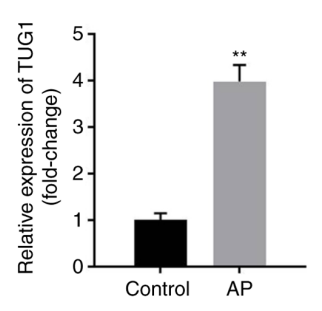

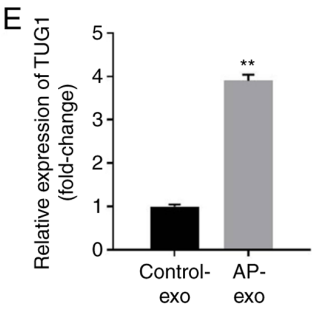

Figure 2. LncRNA TUG1 expression is upregulated in AR42J cells cotreated with caerulein and LPS and in exosomes derived from AR42J cells pretreated with caerulein and LPS. (A) The separation efficiency of exosomes was examined by transmission electron microscopy. (B) The expression levels of CD63 and calnexin in AR42J cells or exosomes derived from AR42J cells were detected by western blotting. (C) The particle sizes of exosomes were measured by Nanosight Tracking Analysis. (D) The expression of TUG1 in AR42J cells was detected by RT-qPCR. (E) The expression of TUG1 in exosomes derived from AR42J cells was detected by RT-qPCR. " P<0.01 vs. control. LncRNA, long non-coding RNA; TUG1, taurine upregulated 1; LPS, lipopolysaccharide; RT-qPCR, reverse transcription-quantitative PCR; AP, acute pancreatitis.

A

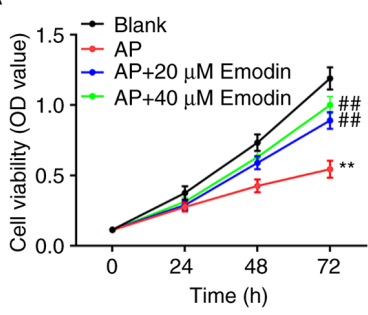

C

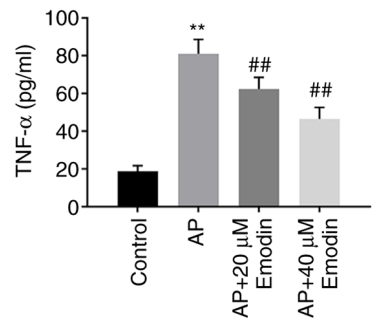

B

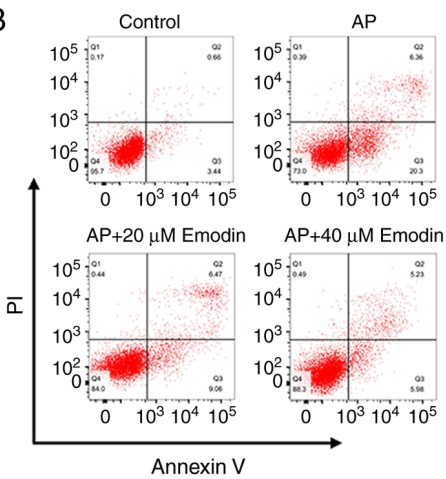

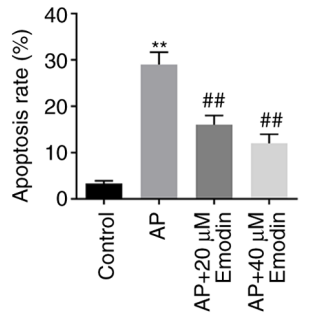

E
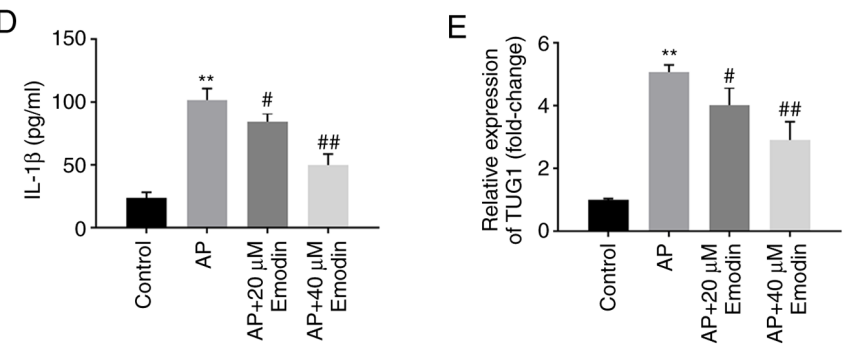

$\mathrm{F}$

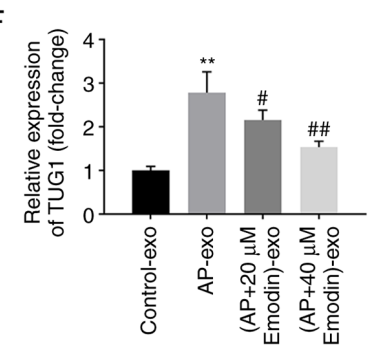

Figure 3. Emodin inhibits the expression of lncRNA TUG1 in cells cotreated with LPS and caerulein and exosomes derived from the aforementioned cell samples. (A) AR42J cells were treated with LPS + caerulein, LPS + caerulein $+20 \mu \mathrm{M}$ emodin or LPS + caerulein $+40 \mu \mathrm{M}$ emodin. Then, the viability of AR42J cells was tested using a Cell Counting Kit- 8 assay. (B) The apoptosis of AR42J cells was tested by flow cytometry. (C) The level of TNF- $\alpha$ in the supernatants of AR42J cells was detected by ELISA. (D) The level of IL-1 $\beta$ in the supernatants of AR42J cells was detected by ELISA. (E) The expression of TUG1 in AR42J cells was measured by RT-qPCR. (F) The expression of TUG1 in exosomes derived from AR42J cells was measured by RT-qPCR. ${ }^{* *} \mathrm{P}<0.01$ vs. control; ${ }^{\#} \mathrm{P}<0.05,{ }^{\# /} \mathrm{P}<0.01$ vs. AP or AP-exo. LncRNA, long non-coding RNA; TUG1, taurine upregulated 1; LPS, lipopolysaccharide; RT-qPCR, reverse transcription-quantitative PCR; AP, acute pancreatitis. 
A

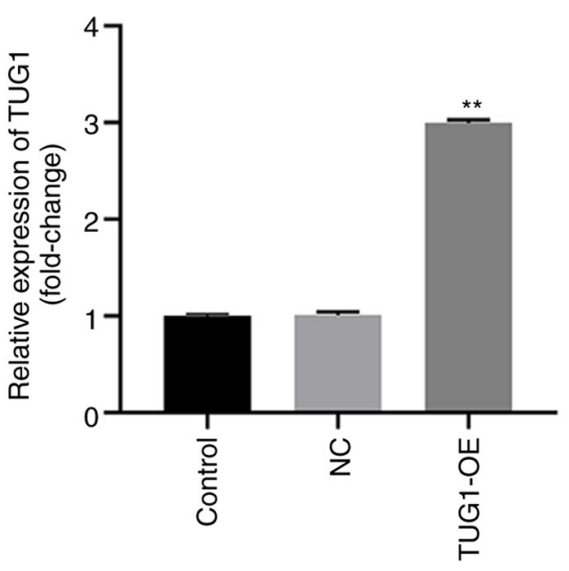

C
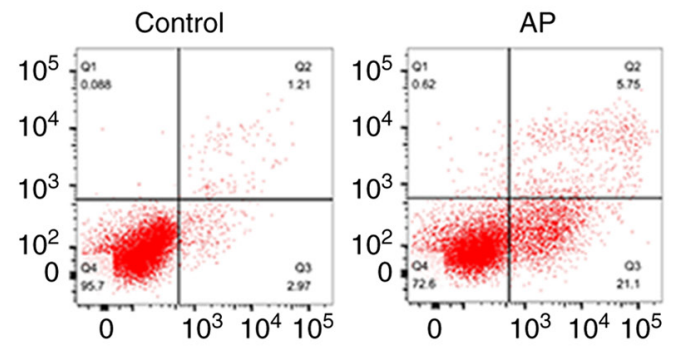

$\overline{0}$

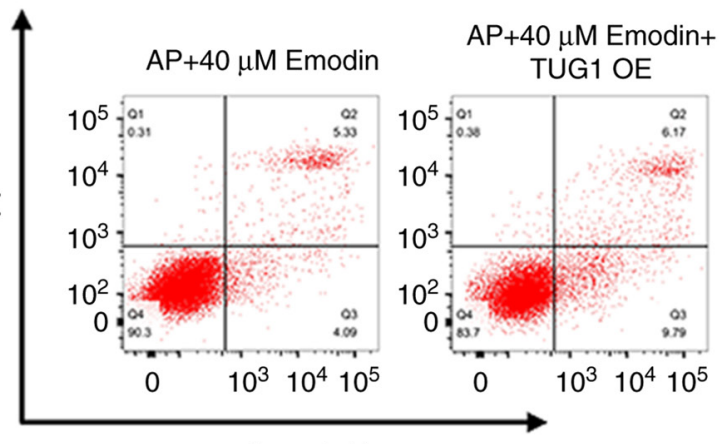

B
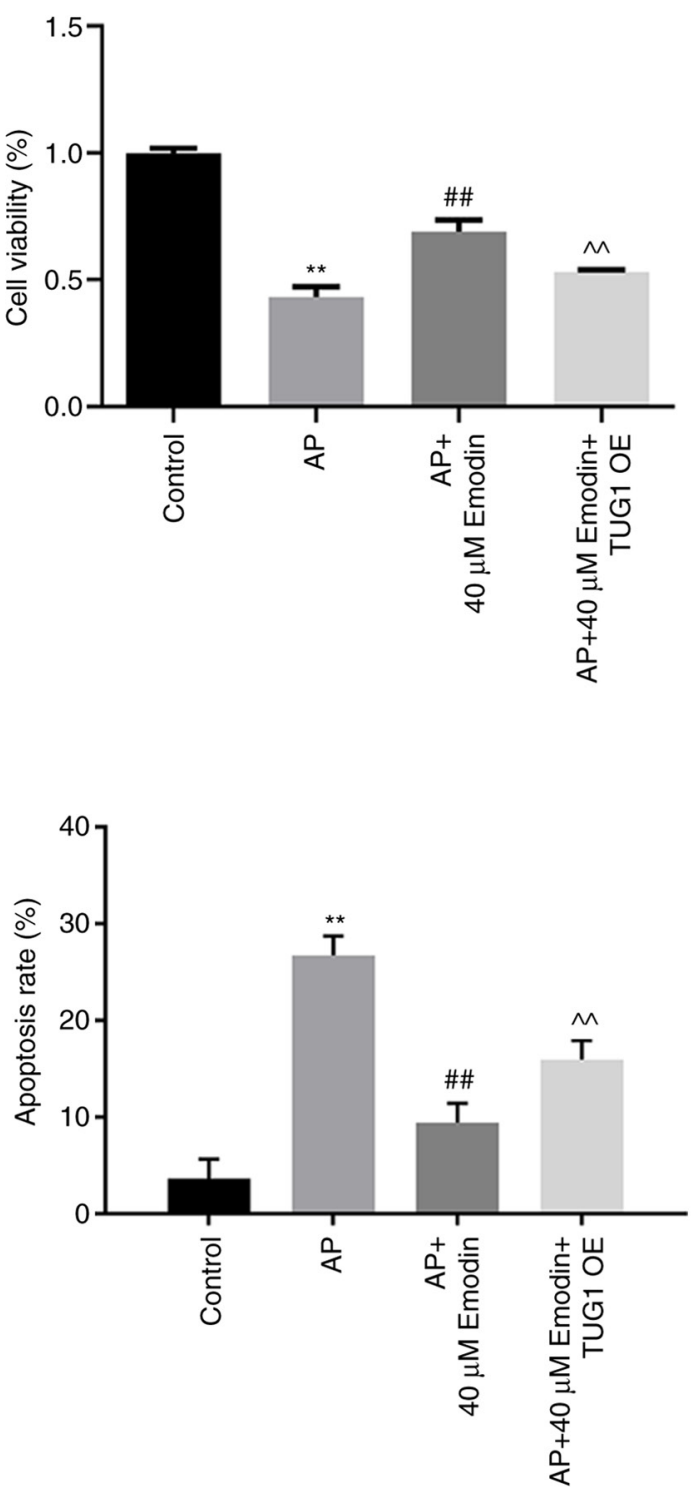

Figure 4. TUG1 overexpression significantly reverses the effect of emodin on the viability of AR42J cells cotreated with caerulein and LPS via inhibiting cell apoptosis. (A) AR42J cells were transfected with pcDNA3.1 or pcDNA3.1-TUG1 for $48 \mathrm{~h}$. Then, the efficiency of cell transfection was detected by RT-qPCR. (B) AR42J cells were treated with LPS + caerulein, LPS + caerulein $+40 \mu \mathrm{M}$ emodin or LPS + caerulein $+40 \mu \mathrm{M}$ emodin + TUG1 OE. The viability of AR42J cells was tested by Cell Counting Kit-8 assay. (C) The apoptosis of AR42J cells was investigated by flow cytometry. ${ }^{* *} \mathrm{P}<0.01$ vs. control; ${ }^{\# \#} \mathrm{P}<0.01$ vs. $\mathrm{AP} ; \wedge \wedge \mathrm{P}<0.01$ vs. AP $+40 \mu \mathrm{M}$ emodin. TUG1, taurine upregulated 1; LPS, lipopolysaccharide; RT-qPCR, reverse transcription-quantitative PCR; AP, acute pancreatitis; OE, overexpression; NC, negative control.

Emodin significantly inhibits the progression of AP in vivo. To further confirm the function of emodin in AP, an in vivo model of AP was established. As indicated in Fig. 6A, notable injury of the pancreas tissue and inflammatory infiltration were observed in AP mice, while emodin markedly reversed this phenomenon. In addition, AP-induced upregulation of IL-6, IL- $1 \beta$ and TNF- $\alpha$ was significantly inhibited in the presence of emodin (Fig. 6B). Overall, emodin significantly inhibited the progression of AP in vivo.

\section{Discussion}

A number of agents have been reported to have anti-inflammatory effects on AP. For instance, Lin et al (37) found Flos Lonicerae Japonicae water extract (FLJWE) could inhibit pseudorabies virus-induced inflammation in RAW264.7 cells. Furthermore, Esmail et al (38) indicated that niclosamide could inhibit inflammation in liver fibrosis. Meanwhile, it has been reported that emodin exhibits anti-inflammatory effects on AP $(10,39)$. In the present study, the results indicated that this compound could inhibit the inflammatory response in AR42J cells cotreated with LPS and caerulein. Moreover, the present study demonstrated that emodin promoted Treg cell differentiation in AP by regulation of TUG1 in exosomes derived from AR42J cells cotreated with caerulein and LPS. Meanwhile, compared with other anti-inflammatory agents (for example, FLJWE and niclosamide), emodin has been confirmed to significantly relieve inflammation of the gastrointestinal tract $(40,41)$. Based on the present data and previous reports, the findings demonstrated the underlying 

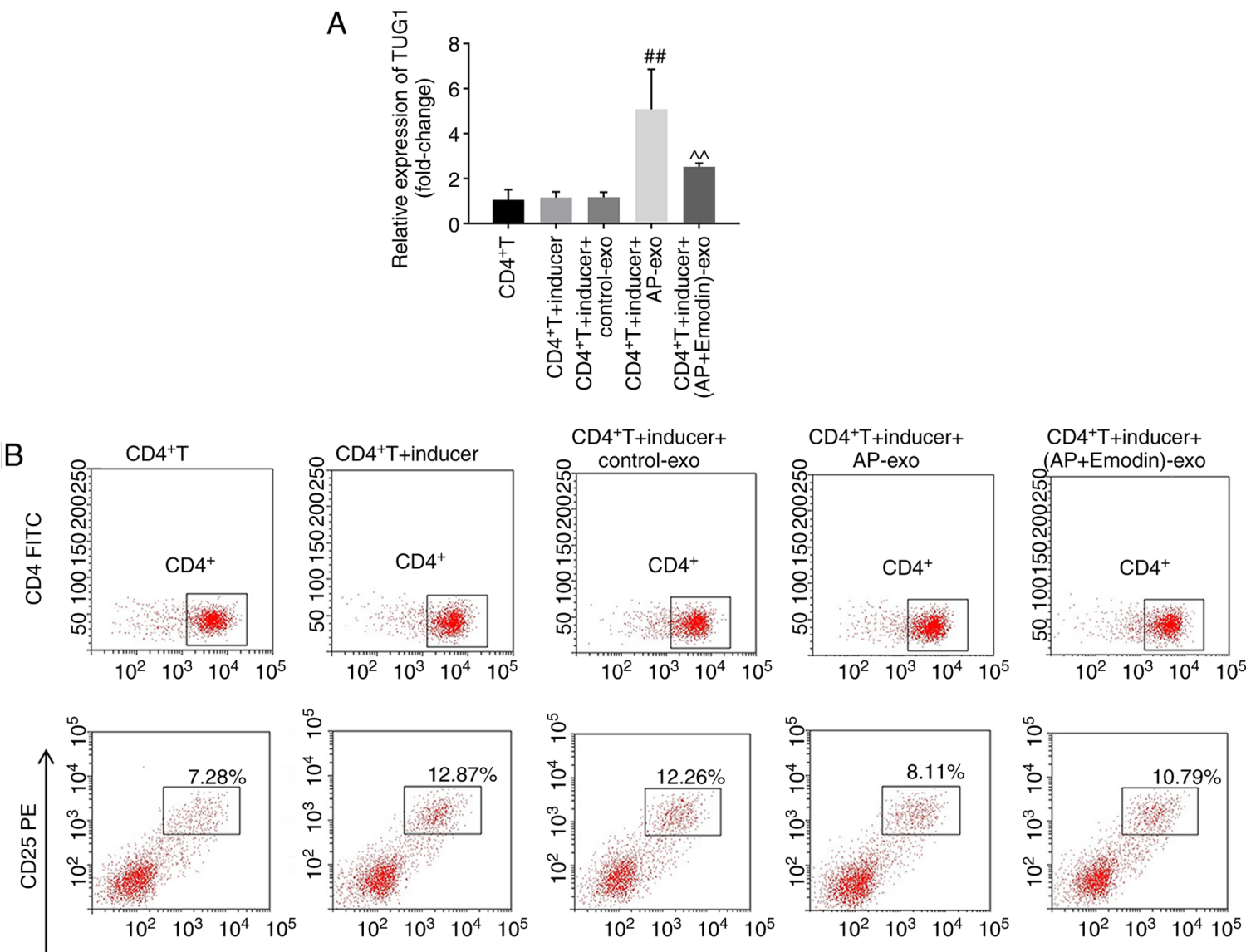

FOXP3 APC
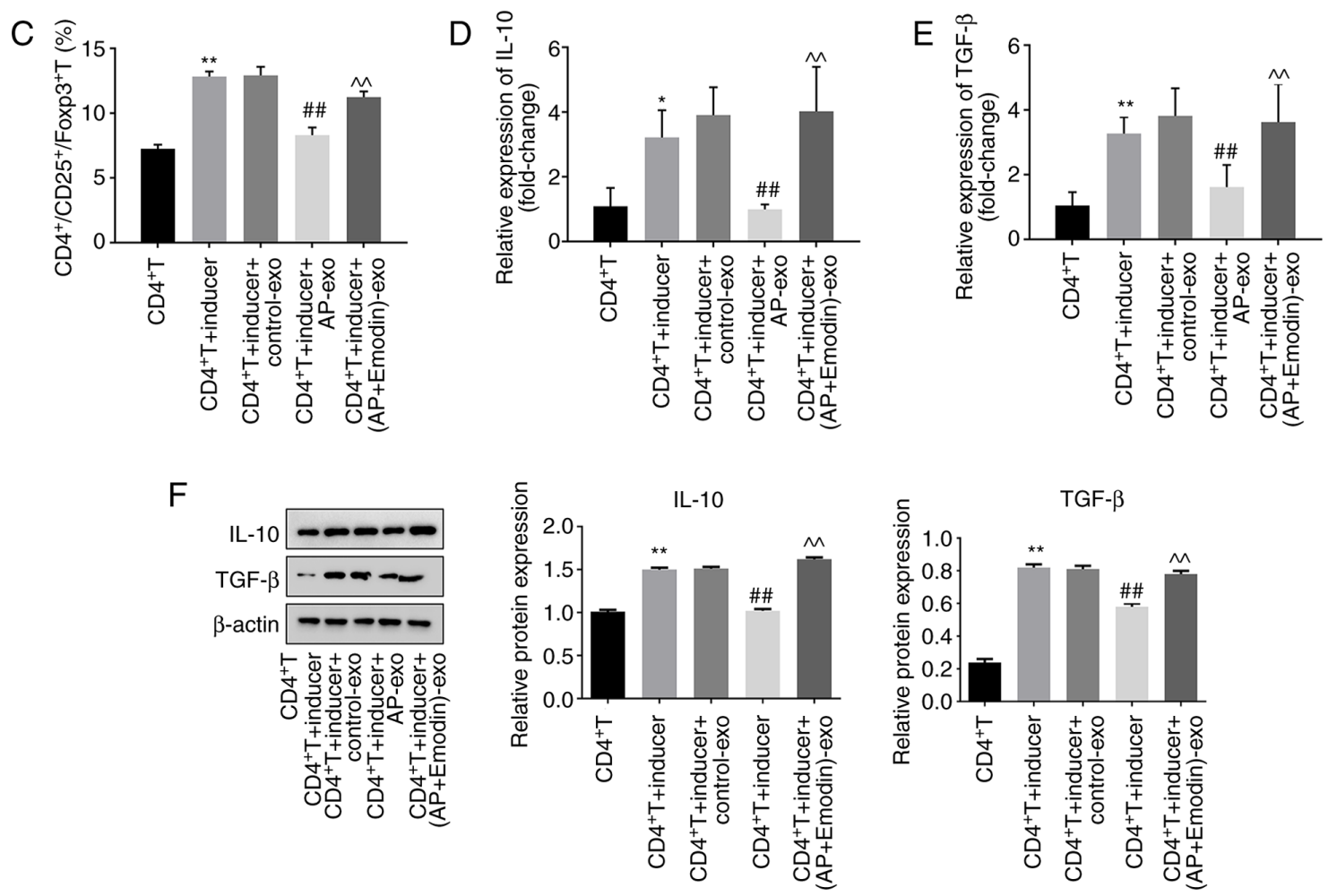

Figure 5. Emodin promotes the differentiation of Treg cells via inhibition of TUG1 in exosomes derived from caerulein and LPS cotreated AR42J cells. CD4 ${ }^{+}$ $\mathrm{T}$ cells were treated with inducer (anti-CD3/anti-CD28 and IL-2), inducer + control-exo, inducer + AP-exo, or inducer + (AP + emodin)-exo. (A) The expression of TUG1 in $\mathrm{CD}^{+} \mathrm{T}$ cells was detected by RT-qPCR. (B and C) The ratio of $\mathrm{CD} 4^{+} / \mathrm{CD} 25^{+} / \mathrm{FOXP} 3^{+} \mathrm{T}$ cells was measured by FACS. (D) The expression of IL-10 in CD4 $4^{+}$cells was detected by RT-qPCR. (E) The expression of TGF- $\beta$ in CD4 ${ }^{+} \mathrm{T}$ cells was detected by RT-qPCR. (F) The protein expression levels of IL-10 and TGF- $\beta$ in CD4 $4^{+} \mathrm{T}$ cells were detected by western blotting. The relative levels were semi-quantified by normalization to $\beta$-actin. ${ }^{*} \mathrm{P}<0.05$, ${ }^{* * *} \mathrm{P}<0.01$ vs. $\mathrm{CD} 4^{+} \mathrm{T}$; ${ }^{\sharp} \mathrm{P}<0.01$ vs. $\mathrm{CD} 4^{+} \mathrm{T}+$ inducer; ${ }^{\wedge} \mathrm{P}<0.01$ vs. $\mathrm{CD} 4^{+} \mathrm{T}+$ inducer $+\mathrm{AP}$-exo. Treg, regulatory $\mathrm{T}$ cell; TUG1, taurine upregulated $1 ; \mathrm{LPS}$, lipopolysaccharide; RT-qPCR, reverse transcription-quantitative PCR; AP, acute pancreatitis. 
A
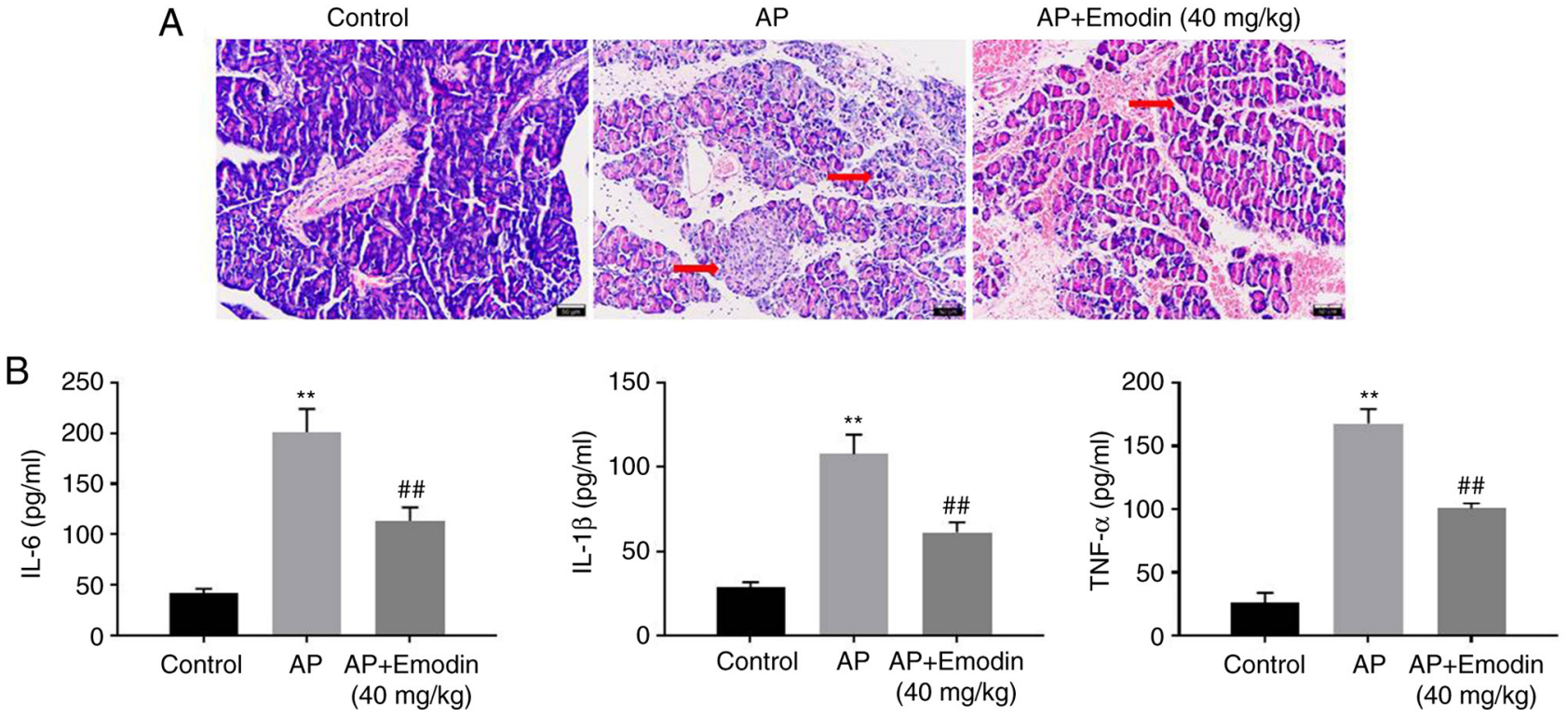

Figure 6. Emodin significantly inhibits the progression of AP in vivo. (A) Tissue injury and inflammatory infiltration in mice were observed by hematoxylin and eosin staining. Red arrows indicate the inflammatory infiltration. (B) The levels of IL- 6 , IL-1 $\beta$ and TNF- $\alpha$ in serum of mice were investigated by ELISA. ${ }^{* *} \mathrm{P}<0.01$ vs. control; ${ }^{\#} \mathrm{P}<0.01$ vs. AP. AP, acute pancreatitis.

mechanism by which emodin mediated the progression of AP, suggesting that it could act as an inhibitor of AP.

lncRNAs are involved in the progression of AP $(1,42)$. The current study demonstrated that TUG1 expression was upregulated in AR42J cells cotreated with caerulein and LPS, suggesting that TUG1 may act as a promoter of AP. Moreover, TUG1 has been shown to regulate disease progression by sponging microRNAs (miRNAs/miRs). For example, Tang et al (43) demonstrated that TUG1 promoted the function of oxidized low-density lipoprotein-treated human aortic vascular smooth muscle cells by activation of the miR-141-3p/receptor tyrosine kinase like orphan receptor 2 axis. Moreover, Pei et al (44) indicated that TUG1 mediated the proliferation and migration of ovarian cancer cells by sponging miR-1299. Therefore, the potential target miRNAs of TUG1 should be investigated in future studies.

Exosomes are known to be secreted by multiple types of cells and may be associated with the progression of multiple diseases $(45,46)$. Accumulating evidence has indicated that exosomes can create an immune suppressive environment by inducing inflammation $(47,48)$. Wang et al $(49)$ suggested that exosomes from mesenchymal stem cells that overexpressed Klotho could reverse apoptosis and NF-kB activation in caerulein-stimulated AR42J cells. Similarly, the findings suggested that exosomes derived from AR42J cells caused upregulation of the expression levels of TUG1 in order to inhibit the immune response during the progression of AP. Furthermore, Salminen et al (50) highlighted that exosomal vesicles enhanced immunosuppression during chronic inflammation by regulation of Treg cell differentiation. The present findings demonstrated that exosomes derived from AR42J cells cotreated with LPS and caerulein reduced the number of $\mathrm{CD} 4{ }^{+} \mathrm{CD} 25^{+} \mathrm{FOXP} 3^{+} \mathrm{T}$ cells, which may lead to the induction of inflammation. Taken together, the data indicated that exosomes were important components of the inflammatory response and acted as important messengers, which mediated the cross-talk between cells. Therefore, emodin promoted Treg cell differentiation by regulating the function of exosomes derived from AR42J cells cotreated with caerulein and LPS.

The current study has the following limitations: i) The underlying mechanism by which exosomes mediated Treg cell differentiation was not fully investigated; ii) the ratio of Th17/Treg cells was not assessed; iii) the mechanism by which emodin regulated TUG1 expression requires further investigation; and iv) the expression of FOXP3 in $\mathrm{CD} 4{ }^{+} \mathrm{CD} 25^{+}$ cells and the effect of emodin on FOXP3 expression in terms of differentiation require further confirmation. Thus, additional investigations are required in future studies.

In summary, the data of the present study indicated that emodin inhibited the progression of AP in vitro by regulation of the expression levels of cellular and exosomal lncRNA TUG1. Therefore, emodin may be useful as a novel agent for the treatment of AP.

\section{Acknowledgements}

Not applicable.

\section{Funding}

This research was supported by the foundation of State Administration of Traditional Chinese Medicine of Zhejiang Province (grant no. 2016ZB064) and Medical Health Science and Technology Project of Zhejiang Provincial Health Commission (grant no. 2019KY478).

\section{Availability of data and materials}

All data generated or analyzed during this study are included in this published article. 


\section{Authors' contributions}

ZC conceived and supervised the present study. XW designed the experiments. $\mathrm{XW}, \mathrm{BH}, \mathrm{XT}$ and $\mathrm{BW}$ performed the experiments. ZC and XW confirm the authenticity of all the raw data. All authors reviewed the results. All authors have read and approved the final version of the manuscript.

\section{Ethics approval and consent to participate}

All procedures performed in this study involving animals were in accordance with the National Institutes of Health Guide for the Care and Use of Laboratory Animals. The animal experiments were approved by the Animal Care and Use Committee of The First Affiliated Hospital of Zhejiang Chinese Medical University (approval no. 20210201003B; Hangzhou, China).

\section{Patient consent for publication}

Not applicable.

\section{Competing interests}

The authors declare that they have no competing interests.

\section{References}

1. Song G, Zhou J, Song R, Liu D, Yu W, Xie W, Ma Z, Gong J, Meng H, Yang $\mathrm{T}$ and Song Z: Long noncoding RNA H19 regulates the therapeutic efficacy of mesenchymal stem cells in rats with severe acute pancreatitis by sponging miR-138-5p and miR-141-3p. Stem Cell Res Ther 11: 420, 2020.

2. Numoto I, Tsurusaki M, Oda T, Yagyu Y, Ishii K and Murakami T: Transcatheter arterial embolization treatment for bleeding visceral artery pseudoaneurysms in patients with pancreatitis or following pancreatic surgery. Cancers (Basel) 12: 2733, 2020.

3. Barreto SG, Habtezion A, Gukovskaya A, Lugea A, Jeon C, Yadav D, Hegyi P, Venglovecz V, Sutton R and Pandol SJ: Critical thresholds: Key to unlocking the door to the prevention and specific treatments for acute pancreatitis. Gut 70: 194-203, 2021.

4. Yu B, Li J, Li N, Zhu Y, Chen Y, He W and Lu N: Progression to recurrent acute pancreatitis after a first attack of acute pancreatitis in adults. Pancreatology 20: 1340-1346, 2020.

5. Ko J, Skudder-Hill L, Cho J, Bharmal SH and Petrov MS: The relationship between abdominal fat phenotypes and insulin resistance in non-obese individuals after acute pancreatitis. Nutrients 12: e1791, 2021

6. Kurihara Y, Maruhashi T, Wada T, Osada M, Oi M, Yamaoka K and Asari Y: Pancreatitis in a patient with severe coronavirus disease pneumonia treated with Veno-venous extracorporeal membrane oxygenation. Intern Med 59: 2903-2906, 2020.

7. Yang SR, Hsu WH, Wu CY, Shang HS, Liu FC, Chen A, Hua KF and Ka SM: Accelerated, severe lupus nephritis benefits from treatment with honokiol by immunoregulation and differentially regulating NF- $\mathrm{B} / \mathrm{NLRP} 3$ inflammasome and sirtuin 1/autophagy axis. FASEB J 34: 13284-13299, 2020.

8. Liu L, Lin Z, Zheng B, Wang L, Zou J, Wu S, Jiang Z, Jin Q, Lai $X$ and Lin P: Reduced intellectual ability in offspring born from preeclamptic mothers: A Prospective cohort study. Risk Manag Healthc Policy 13: 2037-2046, 2020.

9. Guo R, Li Y, Han M, Liu J and Sun Y: Emodin attenuates acute lung injury in Cecal-ligation and puncture rats. Int Immunopharmacol 85: 106626, 2020.

10. Gao Z, Sui J, Fan R, Qu W, Dong X and Sun D: Emodin protects against acute Pancreatitis-Associated lung injury by inhibiting NLPR3 inflammasome activation via Nrf2/HO-1 signaling. Drug Des Devel Ther 14: 1971-1982, 2020.
11. Sun Z, Xue S, Zhang M, Xu H, Hu X, Chen S, Liu Y, Guo M and Cui H: Aberrant NSUN2-mediated $\mathrm{m}^{5} \mathrm{C}$ modification of H19 lncRNA is associated with poor differentiation of hepatocellular carcinoma. Oncogene 39: 6906-6919, 2020.

12. Szikszai K, Krejcik Z, Klema J, Loudova N, Hrustincova A, Belickova M, Hruba M, Vesela J, Stranecky V, Kundrat D, et al: LncRNA profiling reveals that the deregulation of H19, WT1-AS, TCL6, and LEF1-AS1 Is associated with higher-risk myelodysplastic syndrome. Cancers (Basel) 12: 2726, 2020.

13. Zhu X, Qin X, Wang X, Wang Y, Cao W, Zhang J and Chen W: Oral cancer cellderived exosomes modulate natural killer cell activity by regulating the receptors on these cells. Int J Mol Med 46: 2115-2125, 2020

14. Zeng J, Chen JY, Meng J and Chen Z: Inflammation and DNA methylation coregulate the CtBP-PCAF-c-MYC transcriptional complex to activate the expression of a long non-coding RNA CASC2 in acute pancreatitis. Int J Biol Sci 16: 2116-2130, 2020.

15. Xu K and Zhang L: Inhibition of TUG1/miRNA-299-3p axis represses pancreatic cancer malignant progression via suppression of the notch1 pathway. Dig Dis Sci 65: 1748-1760, 2020.

16. Gao Q, Fang X, Chen Y, Li Z and Wang M: Exosomal lncRNA UCA1 from cancer-associated fibroblasts enhances chemoresistance in vulvar squamous cell carcinoma cells. J Obstet Gynaecol Res 47: 73-87, 2020.

17. Zhang X, Gong W, Cao S, Yin J, Zhang J, Cao J and Shen Y: Comprehensive Analysis of Non-coding RNA profiles of exosome-like vesicles from the protoscoleces and hydatid cyst fluid of echinococcus granulosus. Front Cell Infect Microbiol 10: 316,2020

18. Wang D, Xing N, Yang T, Liu J, Zhao H, He J, Ai Y and Yang J: Exosomal lncRNA H19 promotes the progression of hepatocellular carcinoma treated with Propofol via miR-520a-3p/LIMK1 axis. Cancer Med 9: 7218-7230, 2020.

19. Yuan Z, Yang Z, Li W, Wu A, Su Z and Jiang B: Exosome-mediated transfer of long noncoding RNA HOTAIR regulates temozolomide resistance by miR-519a-3p/RRM1 axis in glioblastoma. Cancer Biother Radiopharm: Jul 24, 2020 (Epub ahead of print).

20. Wu XB, Sun HY, Luo ZL, Cheng L, Duan XM and Ren JD: Plasma-derived exosomes contribute to pancreatitis-associated lung injury by triggering NLRP3-dependent pyroptosis in alveolar macrophages. Biochim Biophys Acta Mol Basis Dis 1866: $165685,2020$.

21. Yang L, Chen S, Zhao Q, Sun Y and Nie H: The critical role of Bach2 in shaping the balance between $\mathrm{CD} 4^{+} \mathrm{T}$ cell subsets in immune-mediated diseases. Mediators Inflamm 2019: 2609737, 2019.

22. Qiao Y, Chen J, Ma C, Liu Y, Li P, Wang Y, Hou L and Liu Z: Increased KIF15 expression predicts a poor prognosis in patients with lung adenocarcinoma. Cell Physiol Biochem 51: 1-10, 2018.

23. Guo J, Li Z, Tang D and Zhang J: Th17/Treg imbalance in patients with severe acute pancreatitis: Attenuated by high-volume hemofiltration treatment. Medicine (Baltimore) 99: e21491, 2020

24. Wang D, Tang M, Zong P, Liu H, Zhang T, Liu Y and Zhao Y: miRNA-155 regulates the Th17/Treg ratio by targeting SOCS1 in severe acute pancreatitis. Front Physiol 9: 686, 2018.

25. He Y, Li M, Wujisiguleng, Lv B, Huan Y, Liu B, Wang D, Yu H, Zhang L and Shi Z: Zhenbao Pill reduces Treg cell proportion in acute spinal cord injury rats by regulating TUG1/miR-214/HSP27 axis. Biosci Rep 38: BSR20180895, 2018.

26. Shen Y, Xue CJ, You GL and Liu C: miR-9 alleviated the inflammatory response and apoptosis in caerulein-induced acute pancreatitis by regulating FGF10 and the NF- $\kappa$ B signaling pathway. Exp Ther Med 22: 795, 2021

27. Zhang KK, Yu SS, Li GY, He L and Liang XQ: miR-135a deficiency inhibits the AR42J cells damage in cerulein-induced acute pancreatitis through targeting FAM129A. Pflugers Arch 471: 1519-1527, 2019.

28. Xu C, Luo Y, Ntim M, Quan W, Li Z, Xu Q, Jiang L, Zhang J, Shang D, Li L, et al: Effect of emodin on long non-coding RNA-mRNA networks in rats with severe acute pancreatitis-induced acute lung injury. J Cell Mol Med 25: 1851-1866, 2021.

29. Zhao JY, Wang JQ, Wu L, Zhang F, Chen ZP, Li WD, Cai H and Liu X: Emodin attenuates cell injury and inflammation in pancreatic acinar AR42J cells. J Asian Nat Prod Res 21: 186-195, 2019.

30. Livak KJ and Schmittgen TD: Analysis of relative gene expression data using real-time quantitative PCR and the 2(-Delta Delta $\mathrm{C}(\mathrm{T})$ ) method. Methods 25: 402-408, 2001. 
31. Guo Z, Wang X, Yang Y, Chen W, Zhang K, Teng B, Huang C, Zhao $Q$ and Qiu Z: Hypoxic Tumor-derived exosomal long noncoding RNA UCA1 promotes angiogenesis via miR-96-5p/AMOTL2 in pancreatic cancer. Mol Ther Nucleic Acids 22: 179-195, 2020.

32. Jiang X, Li X, Zheng S, Du G, Ma J, Zhang L, Wang H and Tian J: Comparison study of different indoleamine-2,3 dioxygenase inhibitors from the perspective of pharmacodynamic effects. Int J Immunopathol Pharmacol 34: 2058738420950584, 2020.

33. Fiori A, Uhlig S, Kluter H and Bieback K: Human adipose tissue-derived mesenchymal stromal cells inhibit CD4+ T cell proliferation and induce regulatory $\mathrm{T}$ cells as well as CD127 expression on $\mathrm{CD} 4{ }^{+} \mathrm{CD} 25^{+} \mathrm{T}$ cells. Cells 10: 58, 2021.

34. Wang XD, Yu WL and Sun Y: Activation of AMPK restored impaired autophagy and inhibited inflammation reaction by up-regulating SIRT1 in acute pancreatitis. Life Sci 277: 119435, 2021.

35. Xiang H, Guo F, Tao X, Zhou Q, Xia S, Deng D, Li L and Shang D: Pancreatic ductal deletion of S100A9 alleviates acute pancreatitis by targeting VNN1-mediated ROS release to inhibit NLRP3 activation. Theranostics 11: 4467-4482, 2021.

36. Dai J, He Y, Jiang M, Niu M, Li B, Wu Z, Bao J, Wen L, Wang X and $\mathrm{Hu}$ G: Reg4 regulates pancreatic regeneration following pancreatitis via modulating the Notch signaling. J Cell Physiol. Apr 26, 2021 (Epub ahead of print).

37. Lin HW, Lee YJ, Yang DJ, Hsieh MC, Chen CC, Hsu WL, Chang YY and Liu CW: Anti-inflammatory effects of flos lonicerae japonicae water extract are regulated by the STAT/NF- $\kappa$ B pathway and HO-1 expression in Virus-infected RAW264.7 cells. Int J Med Sci 18: 2285-2293, 2021.

38. Esmail MM, Saeed NM, Michel HE and El-Naga RN: The ameliorative effect of niclosamide on bile duct ligation induced liver fibrosis via suppression of NOTCH and Wnt pathways. Toxicol Lett 347: 23-35, 2021.

39. Xu C, Zhang J, Liu J, Li Z, Liu Z, Luo Y, Xu Q, Wang M, Zhang G, Wang $\mathrm{F}$ and Chen $\mathrm{H}$ : Proteomic analysis reveals the protective effects of emodin on severe acute pancreatitis induced lung injury by inhibiting neutrophil proteases activity. J Proteomics 220: 103760, 2020

40. Xia S, Ni Y, Zhou Q, Liu H, Xiang H, Sui H and Shang D: Emodin attenuates severe acute pancreatitis via antioxidant and anti-inflammatory activity. Inflammation 42: 2129-2138, 2019.
41. Luo S, Deng X, Liu Q, Pan Z, Zhao Z, Zhou L and Luo X: Emodin ameliorates ulcerative colitis by the flagellin-TLR5 dependent pathway in mice. Int Immunopharmacol 59: 269-275, 2018.

42. Chen $X$ and Song D: LncRNA MEG3 participates in caerulein-induced inflammatory injury in human pancreatic cells via regulating miR-195-5p/FGFR2 axis and inactivating NF- $\kappa$ B pathway. Inflammation 44: 160-173, 2021.

43. Tang Y, Hu J, Zhong Z, Liu Y and Wang Y: Long noncoding RNA TUG1 promotes the function in ox-LDL-treated HA-VSMCs via miR-141-3p/ROR2 axis. Cardiovasc Ther 2020: 6758934, 2020.

44. Pei Y, Li K, Lou X, Wu Y, Dong X, Wang W, Li N, Zhang D and Cui W: miR1299/NOTCH3/TUG1 feedback loop contributes to the malignant proliferation of ovarian cancer. Oncol Rep 44: 438-448, 2020 .

45. Zhang C, Zhang C, Xu Y, Li C, Cao Y and Li P: Exosomes derived from human placenta-derived mesenchymal stem cells improve neurologic function by promoting angiogenesis after spinal cord injury. Neurosci Lett 739: 135399, 2020.

46. Colucci M, Ruggiero B, Gianviti A, Rosado MM, Carsetti R, Bracaglia C, De Benedetti F, Emma F and Vivarelli M: IgM on the surface of T cells: A novel biomarker of pediatric-onset systemic lupus erythematosus. Pediatr Nephrol 36: 909-916, 2021.

47. Matikainen S, Nyman TA and Cypryk W: Inflammasomes: Exosomal miRNAs loaded for action. J Cell Biol 219: e202008130, 2020.

48. Elashiry M,Elashiry MM, Elsayed R, Rajendran M, Auersvald C, Zeitoun R, Rashid MH, Ara R, Meghil MM, Liu Y, et al: Dendritic cell derived exosomes loaded with immunoregulatory cargo reprogram local immune responses and inhibit degenerative bone disease in vivo. J Extracell Vesicles 9: 1795362, 2020.

49. Wang N, Ma J, Ren Y, Xiang S and Jia R: Secreted klotho from exosomes alleviates inflammation and apoptosis in acute pancreatitis. Am J Transl Res 11: 3375-3383, 2019.

50. Salminen A, Kaarniranta K and Kauppinen A: Exosomal vesicles enhance immunosuppression in chronic inflammation: Impact in cellular senescence and the aging process. Cell Signal 75: 109771, 2020.

(i) $($ ) This work is licensed under a Creative Commons c. Attribution-NonCommercial-NoDerivatives 4.0 International (CC BY-NC-ND 4.0) License. 